\title{
Identical figures, exposure time and disappearance phenomena under reduced stimulation conditions
}

\author{
RICHARD C. TEES AND LINDA K. MDRE
}

UNIVERSITY OF BRITISH COLUMBIA

The extent to which two identical stimuli in a three-element design disappear together under reduced stimulation conditions was found to be significantly greater than other possible paired disappearances. Moreover, during the course of three observational sessions, the proportion of identicalpair disappearances increased significantly.

Concurrent disappearance of parallel lines and identical forms have been reported when the visual image is stabilized on the retina (Replogle, 1962; Tees, 1961). Similar results have been obtained under reduced stimulation conditions (McKinney, 1963). Moreover, using polygons scaled for similarity and simplified stimulus conditions, Donderi (1966) found the duration of simultaneous disappearance of two polygons increased with an increase in their form-pair similarity.

The above observations have been used in support of Hebb's (1949) association theory of perceptual learning. It has been suggested (Hebb, 1963) that the neural representatives of identical stimuli must contain a higher proportion of cells in common and with reduced sensory input simultaneous disappearances of identical figures would be expected.

The purpose of this investigation was to measure the degree to which two identical forms in a three-element display disappear together in relation to other possible paired-disappearances under reduced stimulation conditions. A related intention was to determine what changes, if any, in these disappearance relationships might take place over several observation sessions. Method

The Ss were 124 college student volunteers. The stimuli were five luminous three-digit and three-letter targets (922, 955, 332, GGR, PPL). The horizontally arranged digits (and letters) were 3 in. high and $1 / 3$ in. thick and equidistant from each other. At the 5-1/2 ft. viewing distance each digit or letter subtended a visual angle of $1.7^{\circ}$. In a darkened, light-tight room, each $\mathrm{S}$ viewed only one of the three-digit targets, monocularly with the right eye for $5 \mathrm{~min}$. The $\mathrm{S}$ was asked to fixate on the center of the target and report all complete digit and letter disappearances.

Ten other randomly assigned Ss were exposed to 332 for $5 \mathrm{~min}$. These $\mathrm{Ss}$ then viewed slides of 3-9 digits (which did not contain either 3 or 2) for $5 \mathrm{~min}$. The slides and the manner of presentation has previously been described (More \& Tees, in press). The Ss were then retested for $5 \mathrm{~min}$. with the luminous target 332 . Finally, one further slide presentation and retest occurred.

\section{Resulis}

The results concerning paired disappearances for the five targets are presented in Table 1. The disappearances were divided into those related to "identical" and "different" stimulus pairs. Disappearances such as -55 and 8-- are evidence for the effect of an association between identical stimuli (e.g.55). Disappearances such as $85-$ and --5 are evidence for an association between the "different" stimulus pair (e.g. 8 and 5). Disappearances of all digits in the triplet simultaneously cannot be attributed to a particular pair of stimuli and are not included. The disappearance of the center stimulus (e.g. 8-5) and the outside stimuli (e.g. -5-) are also not reported. The center digit would be expected to disappear very frequently as a result of fixation; this, in fact, does occur (More \& Tees, in press).

To show that the frequency of identical pair disappearances was significantly different from chance, chi square tests were performed. Identical pairs did disappear and appear together significantly more often than other pairs (see Table 1). The only exception was the letter triplet GGR.

In order to determine what changes in these disappearance relationships might take place over several observation sessions, 10 Ss reported on disappearances for the triplet 332 over the three $5 \mathrm{~min}$. observation sessions and this data is recorded in Table 2.

The hypothesis was tested that differences in the actual number of identical pairs disappearance over the three sessions for the $10 \mathrm{Ss}$ were due to chance. However, a significant increase in identical pairs disappearances was found $\left(\mathrm{X}^{2}=14.4, \mathrm{p}<0.001\right)$. The proposition that significant changes did occur in the proportions of identical pair disappearances was further examined. The results of these $t$ tests are displayed in Table 3 . The mean difference in identical pair proportions between observational sessions 1 and 2 is not significant. How-

Table 1. Mean Disappearance Proportions of Identical Pair Disappearances for Digit and Letter Triplets

\begin{tabular}{lccc} 
Target Triplet & $N$ & $\begin{array}{r}\text { Mean Disappecrance Proportion } \\
\text { (Identical Pair) }\end{array}$ & $X^{2}$ \\
\hline 992 & 10 & .916 & $6.9 *$ \\
855 & 35 & .808 & $13.3^{* *}$ \\
332 & 25 & .845 & $11.9 * *$ \\
GGR & 12 & .807 & 4.5 \\
PPL & 42 & .868 & $22.9 * * *$ \\
\hline
\end{tabular}

* significant at $p<0.05$

** significant at $p<0.01$

** significant at $p<0.001$ 
Table 2.

Changes in Proportions of Identical Pair Disappearances Over Time

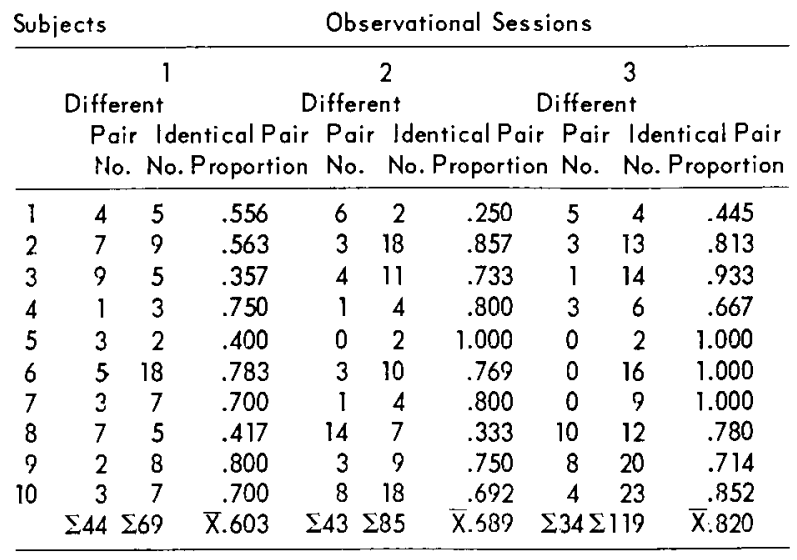

ever, the difference between sessions 2 and 3 just barely misses significance (Needed $t=2.26, p<0.05$ ) and the difference between sessions 1 and 3 does reach significance $(t=2.69, \mathrm{df}=9, \mathrm{p}<0.05)$.

\section{Discussion}

One could assume from Hubel \& Wiesel's (1965) research concerning the neural mediation of form discriminations that with relatively complex forms such as digits or letters similar designs would excite a great number of cells in common. If disappearances under simplified stimulus conditions are a consequence of central process inhibition resulting from reduced stimulus input (Hebb, 1963), then a high degree of neural overlap should result in a high proportion of joint disappearances and appearances for the identical stimulus pairs. Fatigue for the neural representatives of one of the pair would mean fatigue for the cells of the other. In this experiment, in the case of four of the five targets, identical pairs disappeared together significantly more often than different stimulus pairs. Though the differences were not significant for the other one (GGR), the total number and mean proportion indicated that the identical stimulus pair did disappear together very frequently. Examination of the mean proportions themselves (Table 2) reveals that if sufficient Ss had been run on GGR, the results would have likely reached significance. The proportion of identical pair disappearances for the triplet 855 was .808 (significant) for $35 \mathrm{Ss}$ and GGR was .807 for $12 \mathrm{Ss}$ (not significant). Moreover, in the cases of the $10 \mathrm{Ss}$ who were tested over three

Table 3. Tests of Significance of Changes in Proportions of Identical Pair Disappearances for Different Observation Sessions

\begin{tabular}{lcc} 
Observation sessions & Mean difference proportion & $t$ \\
\hline 1 and 2 & 0.096 & 1.17 \\
2 and 3 & 0.122 & 2.22 \\
1 and 3 & 0.218 & $2.69 *$ \\
\hline
\end{tabular}

* significant at $p<0.05$ observation sessions, it is apparent that by the third session, the stimulus situations have become very familiar and the identical pair disappear and reappear as a unit significantly more frequently than originally. With increased familiarity, changes if the stimulus situation itself and its arousal properties must result in less input to the cortex. Compared to different stimulus pairs, identical stimuli would have smaller total cell populations to be stimulated and hence the best opportunity for these cells to become refractory causing visual disappearances.

It should also be noted that the differences in proportions of identical pair disappearances between observational session 1 and 3 reached significance because of the fact that for this particular group of Ss the number (hence the proportion) of identical-pairs compared to different-pair disappearances was relatively low in session 1. Data collected on this triplet (332) for other Ss suggests that the proportion is very often higher. However, it is apparent that increased familiarity in the test situation and the target results in some increase in the proportion of identical-pair disappearances. Other research was carried out in which two digit triplets were used (Tees \& More, in press). One of the triplets was viewed twice while the other was viewed only once. The effect of equal amounts of perceptual learning on the two targets was somewhat different. The perceptual learning was designed to and did result in a significant increase in the number of "different" pair disappearances. The number of "different" paired disappearances was slightly lower for the target viewed twice. The result of the present experiment suggests this difference was due to the differences in targetiamiliarity.

\section{References}

Donderi, D. C. Visual disappearances crused by form similarity. Science, 1966, 152, 99-100.

Hebb, D. O. The organization of behavior. New York: Wiley, 1949. Hebb, D. O. The semiautonomous process: its nature and nurture. Amer. Psychologist, 1963, 18, 16-27.

Hubel, D. H., \& Wiesel, T. N. Receptive fields and functional architecture in two nonstriate visual areas. J. Neurophysiol., $1965,28,229-289$.

McKinney, J. P. Disappearance of luminous designs. Science, $1963,140,403-404$.

More, L. K., \& Tees, R. C. Perceptual learning as a function of the number of repeated exposures to a stimulus. Amer. J. Psychol., in press.

Replogle, A. The effects of similarity on the behaviour of perceived figures. Paper read at EPA, Atlantic City, 1962.

Tees, R. C. The role of field effects in visual perception. Underg. res. prog. Psychol., 1961, 3, 87-96 (McGill University).

Tees, R. C., \& More, L. K. Effect of amount of perceptual learning upon disappearances observed under reduced stimulation conditions. Canad. J. Psychol., in press.

\section{Note}

1. This research was supported with funds granted by the National Research Council of Canada (Grant APA-179) and by the University of British Columbia Faculty of Graduate Studies' Committee on Research. 